\title{
Health-related quality of life in elderly patients hospitalized with chronic heart failure
}

\author{
This article was published in the following Dove Press journal: \\ Clinical Interventions in Aging \\ 14 November 2013 \\ Number of times this article has been viewed
}

\author{
Predrag Erceg ${ }^{1,2}$ \\ Nebojsa Despotovic ${ }^{1,2}$ \\ Dragoslav P Milosevic ${ }^{1,2}$ \\ Ivan Soldatovic ${ }^{3}$ \\ Sanja Zdravkovic ${ }^{2}$ \\ Snezana Tomic ${ }^{2}$ \\ Ivana Markovic ${ }^{2}$ \\ Gordana Mihajlovic ${ }^{2}$ \\ Milan D Brajovic ${ }^{4,5}$ \\ Ognjen Bojovic ${ }^{6}$ \\ Bojana Potic ${ }^{2}$ \\ Mladen Davidovic' \\ 'Department of Gerontology, Faculty \\ of Medicine, University of Belgrade, \\ ${ }^{2}$ Clinical Department of Geriatrics, \\ Zvezdara University Hospital, \\ ${ }^{3}$ Institute of Medical Statistics and \\ Informatics, Faculty of Medicine, \\ ${ }^{4}$ Department of Internal Medicine, \\ Faculty of Dentistry, University of \\ Belgrade, ${ }^{5} \mathrm{Clinical}$ Department of \\ Cardiology, Zvezdara University \\ Hospital, Belgrade, Serbia; \\ ${ }^{6}$ Department of Biomedicine, \\ University of Bergen, Bergen, Norway
}

Correspondence: Predrag Erceg Department of Gerontology, Faculty of Medicine, University of Belgrade,

Dr Subotica 8, I 1000 Belgrade, Serbia

Tel +38 I II 24I 7094

Fax +38 | || 24| 7494

Email predrag.erceg@mfub.bg.ac.rs
Background: Chronic heart failure is a very common condition in the elderly, characterized not only by high mortality rates, but also by a strong impact on health-related quality of life (HRQOL). Previous studies of HRQOL in elderly heart failure subjects have included mostly outpatients, and little is known about determinants of HRQOL in hospitalized elderly population, especially in Serbia. In this study, we tried to identify factors that influence HRQOL in elderly patients hospitalized with chronic heart failure in Serbia.

Methods: The study population consisted of 136 patients aged 65 years or older hospitalized for chronic heart failure. HRQOL was assessed using the Minnesota Living with Heart Failure questionnaire. Predictors of HRQOL were identified by multiple linear regression analysis.

Results: Univariate analysis showed that patients with lower income, a longer history of chronic heart failure, and longer length of hospital stay, as well as those receiving aldosterone antagonists and digoxin, taking multiple medications, in a higher NYHA class, and showing signs of depression and cognitive impairment had significantly worse HRQOL. Presence of depressive symptoms $(P<0.001)$, higher NYHA class $(P=0.021)$, lower income $(P=0.029)$, and longer duration of heart failure $(P=0.049)$ were independent predictors of poor HRQOL.

Conclusion: Depressive symptoms, higher NYHA class, lower income, and longer duration of chronic heart failure are independent predictors of poor HRQOL in elderly patients hospitalized with chronic heart failure in Serbia. Further, there is an association between multiple medication usage and poor HRQOL, as well as a negative impact of cognitive impairment on HRQOL. Hence, measures should be implemented to identify such patients, especially those with depressive symptoms, and appropriate interventions undertaken in order to improve their HRQOL.

Keywords: elderly, heart disease, self-perception of health, depression

\section{Introduction}

Chronic heart failure (CHF) is a very common condition in the aged population, with a prevalence of up to $12 \% .{ }^{1}$ It is characterized by high mortality, which reaches $50 \%$ in the 5 years following diagnosis. ${ }^{2}$ No less importantly, CHF affects daily functioning in elderly patients, ultimately impairing their health-related quality of life (HRQOL). ${ }^{3}$ HRQOL is defined as the patient's subjective perception of the influence of disease on their everyday life. ${ }^{4}$ In patients with CHF, HRQOL may be impaired by symptoms of the disease (dyspnea, fatigue), psychologic disorders (anxiety, depression), adverse effects of drugs, and costs of treatment. ${ }^{4-8}$

Previous studies have shown that HRQOL in CHF patients is predominantly influenced by New York Heart Association (NYHA) class, indicating that those with higher 
NYHA class have poorer HRQOL. ${ }^{3-6,9-12}$ Although left ventricular ejection fraction (LVEF) is an important predictor of survival in CHF patients, data from the literature suggest that HRQOL is equally impaired in patients with preserved and reduced $L V E F{ }^{5,11,13}$ In addition, earlier studies have identified advanced age, female sex, depression, and treatment with aldosterone antagonists as factors having a negative influence on HRQOL in CHF patients, ${ }^{7-10,14}$ while improvement of HRQOL was noted in subjects taking angiotensin-converting enzyme inhibitors and beta-blockers. ${ }^{15}$

Previous studies on HRQOL in elderly CHF patients have included mostly outpatients, , $^{3,9,10,16-21}$ so little is known about determinants of HRQOL in the hospitalized elderly population, ${ }^{22-26}$ especially in Serbia, where only one paper (that covered a younger population) has been published so far. ${ }^{27}$ In addition, studies performed in hospitalized elderly patients with CHF have paid little or no attention to the effects that multiple medication usage, depression, and cognitive impairment, which are very common among elderly patients, have on HRQOL. Accordingly, in this study we tried to identify demographic and clinical variables, including depression, cognitive status, and medication usage, that influence HRQOL in elderly patients hospitalized with CHF in Serbia.

\section{Patients and methods Study population and design}

The study population consisted of 136 consecutive elderly patients hospitalized for $\mathrm{CHF}$ at the geriatric department of Zvezdara University Hospital in Belgrade, Serbia, between February 2009 and October 2011. Inclusion criteria were age $\geq 65$ years and an established diagnosis of CHF. Exclusion criteria were cancer in the terminal phase, endstage renal failure, previous stroke with immobility, and severe dementia. Diagnosis of CHF was made according to the guidelines for the diagnosis and treatment of CHF from the European Society of Cardiology. ${ }^{28}$

\section{Sociodemographic and clinical characteristics}

Patients were interviewed in order to obtain sociodemographic data, ie, age, sex, marital status, educational level, and household information, such as number of household members and income. Clinical data collected from the medical history included duration of CHF, length of hospital stay, history of previous myocardial infarction, angina, hypertension, and diabetes, as well as current medication. NYHA class was determined for each patient according to their symptoms. LVEF was assessed by echocardiography using the modified Simpson's rule.

\section{Health-related quality of life}

HRQOL was assessed using the Serbian version of the Minnesota Living with Heart Failure Questionnaire (MLHFQ), which is one of the most commonly used diseasespecific instruments for measuring HRQOL in heart failure, with proven reliability and validity. ${ }^{29,30}$ The questionnaire consists of 21 items asking how much the disease and its treatment have affected the patient's life in the previous month. Available responses for each question range from 0 (no effect) to 5 (very much). The total score is calculated by adding ratings from all 21 items and can range from 0 to 105 points, with higher scores indicating poorer HRQOL. In addition to total score, MLHFQ measures the physical (eight items; range 0-40) and emotional (five items; range 0-25) dimensions of HRQOL.

\section{Depressive symptoms and cognitive status}

The presence of depressive symptoms was assessed by the five-item Geriatric Depression Scale. ${ }^{31}$ Total score can range from 0 to 5 , with a result $\geq 2$ points indicating possible depression. The presence of cognitive impairment was tested by the Mini-Mental State Examination, and subjects with scores $<25$ were considered to be cognitively impaired. ${ }^{32}$

\section{Statistical analysis}

Continuous variables are presented as the mean \pm standard deviation, while categoric data are expressed as the numbers and percentage. Differences between independent groups were calculated using the Student's $t$-test for normally distributed variables and the Mann-Whitney $U$ test for non-normally distributed variables. Correlations were calculated using Pearson's correlation coefficient for linear relationships, and with Spearman's rank correlation coefficient for nonlinear relationships between two variables. Factors predictive of HRQOL were identified using multiple linear regression analysis. The regression model included variables related to the MLHFQ score with $P<0.10$ calculated in univariate analysis. All $P$-values $<0.05$ were considered to be statistically significant.

\section{Ethical considerations}

All participants gave their written informed consent. The study was approved by the local ethics committee and performed in accordance with the Declaration of Helsinki. 


\section{Results}

\section{Baseline patient characteristics}

The baseline patient characteristics are presented in Table 1 . The mean patient age was 77.8 years, and males comprised the majority. More than two thirds of subjects were in NYHA classes III and IV. The mean LVEF was $40.9 \%$. Depressive symptoms and cognitive impairment were present in more than half of our patients. The mean total MLHFQ score was 50.4.

Table I Baseline patient characteristics $(n=\mid 36)$

\begin{tabular}{|c|c|}
\hline Characteristic & Value \\
\hline Age (years) & $77.8 \pm 5.9$ \\
\hline Male sex & $72(52.9)$ \\
\hline \multicolumn{2}{|l|}{ Marital status } \\
\hline Married & $47(34.6)$ \\
\hline Single, divorced, widowed & $89(65.4)$ \\
\hline \multicolumn{2}{|l|}{ Education } \\
\hline$>12$ years & $27(19.9)$ \\
\hline$\leq 12$ years & $109(80.1)$ \\
\hline Number of household members & $2.4 \pm 1.4$ \\
\hline Household income (monthly, US dollars) & $447.2 \pm 297.7$ \\
\hline Duration of $\mathrm{CHF}$ (months) & $61.9 \pm 71.1$ \\
\hline \multicolumn{2}{|l|}{ Previous } \\
\hline Myocardial infarction & $44(32.4)$ \\
\hline Angina & $80(58.8)$ \\
\hline Hypertension & $101(74.3)$ \\
\hline Diabetes mellitus & $42(30.9)$ \\
\hline Three or more comorbidities & $90(66.2)$ \\
\hline \multicolumn{2}{|l|}{ Current medications } \\
\hline Diuretics & $128(94.1)$ \\
\hline Aldosterone antagonists & $67(49.3)$ \\
\hline ACEls & $104(76.5)$ \\
\hline ARBs & $3(2.2)$ \\
\hline Beta-blockers & $69(50.7)$ \\
\hline Digoxin & $41(30.1)$ \\
\hline Anticoagulants & $51(37.5)$ \\
\hline Number of drugs & $6.9 \pm 2.3$ \\
\hline \multicolumn{2}{|l|}{ NYHA class } \\
\hline I & $2(1.5)$ \\
\hline ॥ & $36(26.5)$ \\
\hline III & $63(46.3)$ \\
\hline IV & $35(25.7)$ \\
\hline LVEF (\%) & $40.9 \pm 11.0$ \\
\hline Depressive symptoms & $76(55.9)$ \\
\hline Cognitive impairment & 7I (52.2) \\
\hline Length of hospital stay (days) & $18.0 \pm 9.5$ \\
\hline \multicolumn{2}{|l|}{ MLHFQ score } \\
\hline Total & $50.4 \pm 19.3$ \\
\hline Physical & $25.3 \pm 9.4$ \\
\hline Emotional & $10.6 \pm 6.5$ \\
\hline
\end{tabular}

Notes: Data are presented as the mean \pm standard deviation or number (\%). Abbreviations: $\mathrm{CHF}$, chronic heart failure; $\mathrm{ACEls}$, angiotensin-converting enzyme inhibitors; ARBs, angiotensin II receptor blockers; NYHA, New York Heart Association; LVEF, left ventricular ejection fraction; MLHFQ, Minnesota Living with Heart Failure questionnaire.

\section{Factors associated with HRQOL}

We have presented demographic and clinical characteristics, as well as medications and their associations with total, physical, and emotional MLHFQ score. Demographic factors related to HRQOL are shown in Table 2. We found no correlation between age and HRQOL, and no significant difference between male and female patients regarding HRQOL. The educational level of patients correlated positively with the physical dimension of HRQOL $(P=0.038)$, but not with total or emotional MLHFQ score. Household income correlated negatively with total $(P=0.013)$ and physical score $(P=0.012)$ on the MLHFQ, but not with the emotional dimension $(P=0.576)$, indicating that patients with higher income had better overall HRQOL and its physical dimension. With regard to number of household members, we found an inverse correlation with the emotional dimension of HRQOL $(P=0.035)$.

Clinical factors related to HRQOL are shown in Table 3. Duration of CHF correlated negatively with HRQOL and its physical dimension $(P=0.010$ and $P=0.011$, respectively), but not with its emotional dimension $(P=0.085)$. We found no difference in HRQOL between patients with and without a history of previous myocardial infarction, angina, hypertension, and diabetes. There was no correlation between number of comorbidities and MLHFQ scores.

Patients with higher NYHA class (III or IV) had worse overall HRQOL, including its physical and emotional dimensions ( $P<0.001, P<0.001$, and $P=0.023$, respectively). We noticed no difference in HRQOL between subjects with preserved and reduced LVEF.

Subjects with depressive symptoms had poorer overall HRQOL, including its physical and emotional domains, than their nondepressive counterparts $(P<0.001, P<0.001$, and $P<0.001$, respectively). Patients with cognitive impairment had worse overall HRQOL and its emotional dimension than those with preserved cognitive function $(P=0.030$ and $P=0.022$, respectively).

Length of hospital stay correlated inversely with overall HRQOL and its emotional dimension $(P=0.021$ and $P=0.020$, respectively).

Current medications and their association with HRQOL are presented in Table 4. Patients receiving aldosterone antagonists and digoxin had worse HRQOL ( $P=0.046$ and $P=0.049$, respectively). Further, patients on aldosterone antagonists had a worse physical dimension of HRQOL $(P=0.048)$. We did not perform a statistical analysis on use of angiotensin II receptor blockers and HRQOL due to the small 
Table 2 Demographic factors associated with health-related quality of life ${ }^{a}$

\begin{tabular}{|c|c|c|c|c|c|c|}
\hline & $\begin{array}{l}\text { Total } \\
\text { MLHFQ score }\end{array}$ & $P$-value & $\begin{array}{l}\text { Physical } \\
\text { MLHFQ score }\end{array}$ & $P$-value & $\begin{array}{l}\text { Emotional } \\
\text { MLHFQ score }\end{array}$ & $P$-value \\
\hline Age & -0.070 & 0.420 & -0.043 & 0.620 & 0.024 & 0.777 \\
\hline \multicolumn{7}{|l|}{ Gender } \\
\hline Male & $48.6 \pm 19.7$ & 0.227 & $24.0 \pm 9.8$ & 0.075 & $10.1 \pm 6.0$ & 0.264 \\
\hline Female & $52.3 \pm 18.7$ & & $26.9 \pm 8.8$ & & $11.3 \pm 7.0$ & \\
\hline \multicolumn{7}{|l|}{ Marital status } \\
\hline Married & $50.9 \pm 20.4$ & 0.810 & $25.1 \pm 9.6$ & 0.810 & $10.4 \pm 6.4$ & 0.824 \\
\hline Unmarried & $50.1 \pm 18.8$ & & $25.5 \pm 9.4$ & & $10.8 \pm 6.6$ & \\
\hline Education & -0.135 & 0.118 & -0.179 & 0.038 & -0.142 & 0.102 \\
\hline Number of household members & 0.121 & 0.161 & 0.081 & 0.347 & 0.181 & 0.035 \\
\hline Household income & -0.252 & 0.013 & -0.254 & 0.012 & -0.057 & 0.576 \\
\hline
\end{tabular}

Notes: anivariate analysis. HRQOL was assessed using the MLHFQ; higher scores represent more impaired HRQOL. Data are presented as the mean \pm standard deviation, Pearson's product-moment correlation coefficient, or Spearman's rank correlation coefficient.

Abbreviations: MLHFQ, Minnesota Living with Heart Failure questionnaire; HRQOL, health-related quality of life.

number of patients involved (2.2\%). We found an inverse correlation between the number of drugs that patients were taking and HRQOL $(P=0.047)$.

Independent predictors of HRQOL are shown in Table 5. Multiple linear regression analysis showed that the presence of depressive symptoms $(S \beta=0.407 ; P<0.001)$, higher NYHA class $(S \beta=0.229 ; P=0.021)$, lower income ( $S \beta=-0.206 ; P=0.029$ ), and longer duration of heart failure ( $S \beta=0.179 ; P=0.049$ ) were independent predictors of poorer HRQOL.

Table 3 Clinical factors associated with health-related quality of life ${ }^{\mathrm{a}}$

\begin{tabular}{|c|c|c|c|c|c|c|}
\hline & $\begin{array}{l}\text { Total } \\
\text { MLHFQ score }\end{array}$ & $P$-value & $\begin{array}{l}\text { Physical } \\
\text { MLHFQ score }\end{array}$ & $P$-value & $\begin{array}{l}\text { Emotional } \\
\text { MLHFQ score }\end{array}$ & $P$-value \\
\hline Duration of $\mathrm{CHF}$ & 0.224 & 0.010 & 0.223 & 0.011 & 0.151 & 0.085 \\
\hline \multicolumn{7}{|l|}{ Previous MI } \\
\hline Yes & $52.0 \pm 19.0$ & 0.373 & $25.5 \pm 10.3$ & 0.684 & $11.2 \pm 6.2$ & 0.418 \\
\hline No & $49.6 \pm 19.4$ & & $25.3 \pm 9.0$ & & $10.4 \pm 6.6$ & \\
\hline \multicolumn{7}{|l|}{ Previous AP } \\
\hline Yes & $51.6 \pm 19.0$ & 0.325 & $25.8 \pm 9.9$ & 0.344 & $10.8 \pm 6.6$ & 0.796 \\
\hline No & $48.6 \pm 19.6$ & & $24.7 \pm 8.7$ & & $10.5 \pm 6.4$ & \\
\hline \multicolumn{7}{|l|}{ Hypertension } \\
\hline Yes & $49.1 \pm 19.9$ & 0.130 & $24.8 \pm 9.4$ & 0.255 & $10.1 \pm 6.5$ & 0.084 \\
\hline No & $54.0 \pm 17.1$ & & $26.9 \pm 9.5$ & & $12.2 \pm 6.4$ & \\
\hline \multicolumn{7}{|l|}{ Diabetes mellitus } \\
\hline Yes & $49.8 \pm 17.9$ & 0.904 & $24.0 \pm 8.9$ & 0.180 & $11.3 \pm 6.7$ & 0.365 \\
\hline No & $50.6 \pm 19.9$ & & $25.9 \pm 9.6$ & & $10.3 \pm 6.4$ & \\
\hline Number of comorbidities & -0.053 & 0.538 & -0.045 & 0.604 & -0.039 & 0.649 \\
\hline \multicolumn{7}{|l|}{ NYHA class } \\
\hline I or II & $39.3 \pm 18.2$ & $<0.001$ & $19.3 \pm 9.8$ & $<0.00$ I & $8.5 \pm 5.5$ & 0.023 \\
\hline III or IV & $54.7 \pm 18.0$ & & $27.7 \pm 8.2$ & & $11.5 \pm 6.6$ & \\
\hline \multicolumn{7}{|l|}{ LVEF (\%) } \\
\hline$\geq 40$ & $49.3 \pm 18.7$ & $0.66 \mathrm{I}$ & $25.1 \pm 9.1$ & 0.699 & $10.7 \pm 6.4$ & 0.568 \\
\hline$<40$ & $51.5 \pm 19.9$ & & $25.5 \pm 9.9$ & & $10.4 \pm 6.6$ & \\
\hline \multicolumn{7}{|l|}{ Depressive symptoms } \\
\hline Yes & $57.9 \pm 17.6$ & $<0.001$ & $28.5 \pm 8.9$ & $<0.00$ I & $13.1 \pm 6.4$ & $<0.001$ \\
\hline No & $40.9 \pm 17.1$ & & $21.4 \pm 8.6$ & & $7.5 \pm 5.0$ & \\
\hline \multicolumn{7}{|l|}{ Cognitive impairment } \\
\hline Yes & $53.8 \pm 20.7$ & 0.030 & $26.6 \pm 9.8$ & 0.062 & $12.1 \pm 7.2$ & 0.022 \\
\hline No & $46.7 \pm 17.0$ & & $24.0 \pm 8.9$ & & $9.1 \pm 5.2$ & \\
\hline Length of hospital stay & 0.198 & 0.021 & 0.162 & 0.060 & 0.199 & 0.020 \\
\hline
\end{tabular}

Notes: ${ }^{a}$ Univariate analysis. HRQOL was assessed using the Minnesota Living with Heart Failure questionnaire; higher scores represent more impaired HRQOL. Data are presented as the mean \pm standard deviation, Pearson's product-moment correlation coefficient, or Spearman's rank correlation coefficient.

Abbreviations: MLHFQ, Minnesota Living with Heart Failure questionnaire; CHF, chronic heart failure; MI, myocardial infarction; AP, angina pectoris; NYHA, New York Heart Association; LVEF, left ventricular ejection fraction; HRQOL, health-related quality of life. 
Table 4 Current medications associated with health-related quality of life ${ }^{\mathrm{a}}$

\begin{tabular}{|c|c|c|c|c|c|c|}
\hline & $\begin{array}{l}\text { Total } \\
\text { MLHFQ score }\end{array}$ & $P$-value & $\begin{array}{l}\text { Physical } \\
\text { MLHFQ score }\end{array}$ & $P$-value & $\begin{array}{l}\text { Emotional } \\
\text { MLHFQ score }\end{array}$ & $P$-value \\
\hline \multicolumn{7}{|l|}{ Diuretics } \\
\hline Yes & $51.1 \pm 19.4$ & 0.060 & $25.6 \pm 9.4$ & 0.109 & $10.8 \pm 6.6$ & 0.496 \\
\hline No & $38.4 \pm 13.9$ & & $20.6 \pm 8.9$ & & $8.9 \pm 4.1$ & \\
\hline \multicolumn{7}{|c|}{ Aldosterone antagonists } \\
\hline Yes & $53.7 \pm 20.2$ & 0.046 & $26.9 \pm 9.3$ & 0.048 & II. $4 \pm 7.0$ & 0.231 \\
\hline No & $47.2 \pm 17.9$ & & $23.8 \pm 9.3$ & & $9.9 \pm 6.0$ & \\
\hline \multicolumn{7}{|l|}{ ACEls } \\
\hline Yes & $50.8 \pm 20.2$ & 0.731 & $25.0 \pm 9.5$ & 0.443 & II.I \pm 6.7 & 0.230 \\
\hline No & $49.0 \pm 16.2$ & & $26.4 \pm 9.3$ & & $9.2 \pm 5.6$ & \\
\hline \multicolumn{7}{|l|}{ Beta-blockers } \\
\hline Yes & $49.6 \pm 21.4$ & 0.555 & $24.4 \pm 10.0$ & 0.272 & $10.9 \pm 7.0$ & 0.709 \\
\hline No & $51.2 \pm 17.0$ & & $26.3 \pm 8.7$ & & $10.4 \pm 5.9$ & \\
\hline \multicolumn{7}{|l|}{ Digoxin } \\
\hline Yes & $54.5 \pm 17.8$ & 0.049 & $27.2 \pm 9.0$ & 0.128 & $12.1 \pm 6.8$ & 0.115 \\
\hline No & $48.6 \pm 19.7$ & & $24.6 \pm 9.5$ & & $10.0 \pm 6.3$ & \\
\hline \multicolumn{7}{|l|}{ Anticoagulants } \\
\hline Yes & $49.6 \pm 19.0$ & 0.681 & $24.3 \pm 8.8$ & 0.219 & $10.5 \pm 6.6$ & 0.751 \\
\hline No & $50.8 \pm 19.5$ & & $26.0 \pm 9.8$ & & $10.7 \pm 6.4$ & \\
\hline Number of drugs & 0.170 & 0.047 & 0.146 & 0.090 & 0.119 & 0.168 \\
\hline
\end{tabular}

Notes: anivariate analysis. HRQOL was assessed using the Minnesota Living with Heart Failure questionnaire; higher scores represent more impaired HRQOL. Data are presented as the mean \pm standard deviation or Spearman's rank correlation coefficient.

Abbreviations: MLHFQ, Minnesota Living with Heart Failure questionnaire; ACEls, angiotensin-converting enzyme inhibitors; HRQOL, health-related quality of life.

\section{Discussion}

To our knowledge, this study is the first to assess determinants of HRQOL in elderly patients with heart failure in Serbia, and one of only few that have examined HRQOL in the hospital setting. ${ }^{12,22-26}$ We used MLHFQ to evaluate HRQOL in our subjects. The mean MLHFQ score in our patients was higher than values reported by the majority of other studies, indicating poorer HRQOL in our study population. ${ }^{5,10,11,24}$ Reasons for this finding lie in the fact that more than two thirds of our subjects were in NYHA class III or IV, as well as in the negative impact of hospitalization on HRQOL. ${ }^{33}$

Table 5 Independent predictors of health-related quality of life ${ }^{a}$

\begin{tabular}{lll}
\hline & $\boldsymbol{S} \beta$ & $\boldsymbol{P}$-value \\
\hline Depressive symptoms & 0.407 & $<0.00 \mathrm{I}$ \\
NYHA class & 0.229 & 0.021 \\
Duration of CHF & 0.179 & 0.049 \\
Digoxin & 0.139 & 0.125 \\
Income & -0.206 & 0.029 \\
Length of hospital stay & 0.105 & 0.240 \\
Diuretics & -0.039 & 0.682 \\
Cognitive impairment & 0.005 & 0.959 \\
Aldosterone antagonists & -0.023 & $0.81 \mathrm{I}$ \\
Number of drugs & 0.027 & 0.784 \\
\hline
\end{tabular}

Notes: aultiple linear regression analysis. $R^{2}=0.402 ; R^{2}$ (adjusted) $=0.330$. HRQOL was assessed using the Minnesota Living with Heart Failure questionnaire.

Abbreviations: HRQOL, health-related quality of life; NYHA, New York Heart Association; $S \beta$, standard partial regression coefficient; $C H F$, chronic heart failure; $R^{2}$, coefficient of determination.
Our patients were older than the subjects included in most previous studies. ${ }^{3,5,6,11-14}$ We found no correlation between age and HRQOL, which is in accordance with the findings of Kato et $\mathrm{al}^{5}$ and Westlake et al. ${ }^{6}$ Other authors have found either a positive ${ }^{3,13}$ or a negative association between age and HRQOL. ${ }^{10,11}$ We did not observe sex differences in MLFHQ score, which is consistent with the findings of Heo et al, ${ }^{3}$ while other studies have reported worse HRQOL in women. ${ }^{5,9-11,13}$ Marital status had no influence on HRQOL in our subjects, which is similar to the findings reported by Kato et $\mathrm{al}^{5}$ and Westlake and $a 1,{ }^{6}$ and different from the results published by Luttik et al, who found better HRQOL in married subjects. ${ }^{34}$ The education level of our patients correlated negatively only with physical MLHFQ score, but not with total or emotional score, suggesting that more highly educated subjects have a better physical HRQOL dimension. This is in accordance with the findings of Barbareschi et al, who reported better physical HRQOL in more highly educated patients. ${ }^{35}$ We found no association between number of household members and total or physical MLHFQ score, which is similar to the results of Kato et $\mathrm{al}^{5}$ but different from the findings of Luttik et al, who reported poorer HRQOL in patients living alone. ${ }^{34}$ Our study shows an inverse correlation between number of family members and the emotional dimension of HRQOL, which is in contrast with the findings of Franzen et al, who reported a similar emotional dimension of HRQOL in patients living 
alone and those living with family. ${ }^{10}$ Our findings indicate that a higher household income is associated with better overall HRQOL and its physical but not emotional dimension, so correspond partially with the results of Clark et al, who observed better physical and emotional domains of HRQOL in subjects with higher income. ${ }^{36}$

The average length of CHF prior to study enrolment was a little more than 5 years, which is similar to the findings of Allen et $\mathrm{al}^{12}$ and longer than indicated by other authors. ${ }^{5} \mathrm{We}$ found an inverse correlation between duration of CHF and HRQOL and its physical domain, which is consistent with the results published by Allen et $\mathrm{al}^{12}$ and differs from those of Kato et al, who found no significant relationship between length of CHF and HRQOL. 5

In our study, a history of prior myocardial infarction, angina, hypertension, and diabetes was not associated with worse HRQOL. Previous studies have demonstrated that $\mathrm{CHF}$ of ischemic etiology is not associated with worse HRQOL, ${ }^{5,11}$ a finding consistent with ours, while Lewis et al found poorer HRQOL in CHF patients with angina. ${ }^{13}$ Data from the literature do not suggest a relationship between hypertension and HRQOL in CHF, which is in accordance with our results. ${ }^{10,11}$ Franzen et $\mathrm{al}^{10}$ found poorer HRQOL in patients with diabetes and $\mathrm{CHF}$, while Kato et $\mathrm{al}^{5}$ did not find any such association, the latter finding being similar to our results. Our study did not find any correlation between number of comorbidities and MLHFQ scores, which is different from the results of Gott et al, who reported poorer HRQOL in subjects with two or more coexisting diseases. ${ }^{9}$

This study shows that patients with higher NYHA class had worse HRQOL, including its physical and emotional domains, which is consistent with the results of previous studies. $5,6,9,10,12,13$ This finding is not surprising, given that the NYHA classification is based on symptoms of heart failure and the physical limitations of the disease as experienced by patients, and thereby reflects their HRQOL. We observed similar HRQOL in patients with preserved and reduced LVEF, which is in accordance with results published by others. ${ }^{5,11-13}$

Depressive symptoms were present in more than one half of our patients. Previous studies have reported diverse prevalences of depression in patients hospitalized with heart failure (35\%-70\%) because of the different patient selection criteria and diagnostic tools used. ${ }^{7}$ Our patients with depressive symptoms had worse HRQOL than nondepressive subjects, which is consistent with findings published by others. ${ }^{5,9,14}$ Data from the literature suggest that depression is associated with a greater number and over-reporting of symptoms in $\mathrm{CHF}$ patients, which is a possible mechanism for poor HRQOL in such patients. ${ }^{37}$ There is evidence that treatment of depression could improve HRQOL in CHF patients. ${ }^{37}$

More than half of our subjects had signs of cognitive impairment, which is similar to the finding reported by Heckman et al. ${ }^{38}$ Our study indicates that cognitive impairment is related to poorer HRQOL, while Pressler et al did not find significant relationship between these variables. ${ }^{39}$ Possible reasons for reduced HRQOL in patients with cognitive impairment might be poor adherence with medical therapy, frequent coexistence of depression, and different interpretation of symptoms in such a population. ${ }^{38-40}$ We suggest screening for cognitive impairment in elderly patients with CHF, because data in the literature indicate that optimizing therapy for heart failure could possibly improve cognitive function. ${ }^{38}$

Our study shows that a longer length of hospital stay is associated with worse overall HRQOL and its emotional domain. Although the impact of hospitalization on HRQOL in the elderly is known, ${ }^{33}$ previous studies have not assessed the influence of length of hospital stay on HRQOL in CHF patients. The possible influence of longer length of hospital stay on HRQOL could in fact be that prolonged hospitalization may lead to functional decline, worsening of cognitive impairment, and increased risk of iatrogenic injury. ${ }^{33}$

Regarding medication, we found that patients receiving aldosterone antagonists and digoxin had worse HRQOL. Our results are consistent with those reported by Berry et $\mathrm{al},{ }^{8}$ who found worse HRQOL in CHF patients taking aldosterone antagonists, but different from those of other authors who found no association between use of digoxin and HRQOL. ${ }^{5,41}$

Previous studies have shown a beneficial effect of angiotensin-converting enzyme inhibitors and angiotensin II receptor blockers on HRQOL and a trend towards better HRQOL in patients receiving beta-blockers, which was not confirmed in our study. ${ }^{15,42,43}$ We found an inverse correlation between the number of drugs that patients were taking and HRQOL. To the best of our knowledge, there are no previous papers published regarding this issue in CHF. However, polypharmacy in the elderly, and in patients with CHF, leads to unpredictable drug interactions and more frequent adverse effects, which might affect HRQOL. ${ }^{44,45}$ Bearing that in mind, we propose that clinicians should carefully review medication in patients with $\mathrm{CHF}$ and avoid potentially unnecessary therapy.

The results of multiple linear regression analysis in our study showed that the presence of depressive symptoms, higher NYHA class, lower income, and longer duration of heart failure were independent predictors of poor HRQOL, with depression being identified as probably the most influential factor affecting HRQOL in elderly patients with 
CHF. Considering the results obtained from this study and the previously published data, which point to depression as a common condition with a negative impact on HRQOL in patients with CHF, we propose that measuring HRQOL and screening for symptoms of depression in the elderly with CHF should be routine in everyday clinical practice in order to detect such patients and target them for appropriate intervention.

While previous studies have shown that cardiac resynchronization therapy, along with certain disease management and educational programs, are the only interventions that improve HRQOL in patients with heart failure, ${ }^{46}$ results from studies performed in the elderly do not give us strong evidence of possible benefits from such interventions on HRQOL. ${ }^{17}$ Therefore, more research is needed in the future. Considering that elderly patients with $\mathrm{CHF}$ often have a complex profile characterized by depression, cognitive impairment, multiple comorbidities, and polypharmacy, we suggest that the design of future interventional studies on HRQOL in this population include comprehensive geriatric assessment and follow-up, which might improve HRQOL in this vulnerable population.

\section{Study limitations}

This study has several limitations. First, it is a single-center study performed in hospitalized elderly patients in one country, so the findings may not be generalizable. Second, we used only one disease-specific instrument to measure HRQOL (ie, the MLHFQ). Complementary use of other instruments, such as a generic HRQOL questionnaire (the Medical Outcomes Study Short-Form 36) or the disease-specific Kansas City Cardiomyopathy Questionnaire, would probably give us more insight into the HRQOL of our patients. ${ }^{47,48}$ Further, although the MLHFQ is one of the most recommended and commonly used questionnaires for measuring HRQOL in heart failure, ${ }^{49}$ it has been used in only a small number of studies in hospitalized patients in the past and its reliability and validity is not as tested in this population as it is in outpatients. ${ }^{23,24,50}$ With regard to questionnaires canvassing depression, we used only the five-item Geriatric Depression Scale and not other well established and widely used instruments, such as the Beck Depression Inventory or the Medical Outcome Study-Depression questionnaire. ${ }^{51}$ Third, we did not compare the HRQOL of our subjects with that in younger heart failure patients or in the elderly without CHF. Finally, we did not perform subgroup analysis by type of heart failure (eg, diastolic versus systolic), although diastolic dysfunction is a common finding in elderly patients with $\mathrm{CHF}^{11}$ Instead, we compared subjects with preserved $(\geq 40 \%)$ and reduced $(<40 \%)$ LVEF.

\section{Conclusion}

Our study indicates that the presence of depressive symptoms, higher NYHA functional class, lower income, and longer duration of CHF are independent predictors of poor HRQOL in elderly patients hospitalized with CHF in Serbia. Further, we have highlighted the association between multiple medication usage and poor HRQOL, as well as the negative impact of cognitive impairment on HRQOL. Therefore, certain measures should be implemented to identify such patients, especially those with depressive symptoms, and appropriate interventions should be taken in order to improve their HRQOL.

\section{Disclosure}

The authors report no conflicts of interest in this work.

\section{References}

1. Curtis LH, Whellan DJ, Hammill BG, et al. Incidence and prevalence of heart failure in elderly persons,1994-2003. Arch Intern Med. 2008;168(4):418-424.

2. Roger VL, Weston SA, Redfield MM, et al. Trends in heart failure incidence and survival in a community-based population. JAMA. 2004;292(3):344-350.

3. Heo S, Moser DK, Lennie TA, Zambroski CH, Chung ML. Comparison of health-related quality of life between older adults with heart failure and healthy older adults. Heart Lung. 2007;36(1):16-24.

4. Rector TS, Anand IS, Cohn JN. Relationships between clinical assessments and patients' perceptions of the effects of heart failure on their quality of life. J Card Fail. 2006;12(2):87-92.

5. Kato N, Kinugawa K, Seki S, et al. Quality of life as an independent predictor for cardiac events and death in patients with heart failure. Circ J. 2011;75(7):1661-1669.

6. Westlake C, Dracup K, Creaser J, et al. Correlates of health-related quality of life in patients with heart failure. Heart Lung. 2002;31(2): 85-93.

7. Nair N, Farmer C, Gongora E, Dehmer GJ. Commonality between depression and heart failure. Am J Cardiol. 2012;109(5):768-772.

8. Berry C, Murphy NF, De Vito G, et al. Effects of aldosterone receptor blockade in patients with mild-moderate heart failure taking a betablocker. Eur J Heart Fail. 2007;9(4):429-434.

9. Gott M, Barnes S, Parker C, et al. Predictors of the quality of life of older people with heart failure recruited from primary care. Age Ageing. 2006;35(2):172-177.

10. Franzen K, Saveman BI, Blomqvist K. Predictors for health related quality of life in persons 65 years or older with chronic heart failure. Eur J Cardiovasc Nurs. 2007;6(2):112-120.

11. Rao A, Asadi-Lari M, Walsh J, Wilcox R, Gray D. Quality of life in patients with signs and symptoms of heart failure-does systolic function matter? J Card Fail. 2006;12(9):677-683.

12. Allen LA, Gheorghiade M, Reid KJ, et al. Identifying patients hospitalized with heart failure at risk for unfavorable future quality of life. Circ Cardiovasc Qual Outcomes. 2011;4(4):389-398.

13. Lewis EF, Lamas GA, O'Meara E, et al; CHARM Investigators. Characterization of health-related quality of life in heart failure patients with preserved versus low ejection fraction in CHARM. Eur J Heart Fail. 2007;9(1):83-91.

14. Sullivan M, Levy WC, Russo JE, Spertus JA. Depression and health status in patients with advanced heart failure: a prospective study in tertiary care. J Card Fail. 2004;10(5):390-396.

15. Dobre D, de Jongste MJ, Haaijer-Ruskamp FM, Sanderman R, van Veldhuisen DJ, Ranchor AV. The enigma of quality of life in patients with heart failure. Int J Cardiol. 2008;125(3):407-409. 
16. Hägglund L, Boman K, Olofsson M, Brulin C. Fatigue and healthrelated quality of life in elderly patients with and without heart failure in primary healthcare. Eur J Cardiovasc Nurs. 2007;6(3):208-215.

17. Grady KL, Halvey K. Quality of life in elderly heart failure patients. J Geriatr Cardiol. 2006;3(4):227-236.

18. Pihl E, Jacobsson A, Fridlund B, Strömberg A, Mårtensson J. Depression and health-related quality of life in elderly patients suffering from heart failure and their spouses: a comparative study. Eur J Heart Fail. 2005;7(4):583-589.

19. Franzén K, Blomqvist K, Saveman BI. Impact of chronic heart failure on elderly persons' daily life: a validation study. Eur J Cardiovasc Nurs. 2006;5(2):137-145.

20. Son YJ, Song Y, Nam S, Shin WY, Lee SJ, Jin DK. Factors associated with health-related quality of life in elderly Korean patients with heart failure. J Cardiovasc Nurs. 2012;27(6):528-538.

21. Johansson P, Broström A, Dahlström U, Alehagen U. Global perceived health and health-related quality of life in elderly primary care patients with symptoms of heart failure. Eur J Cardiovasc Nurs. 2008;7(4): 269-276.

22. Ekman I, Fagerberg B, Lundman B. Health-related quality of life and sense of coherence among elderly patients with severe chronic heart failure in comparison with healthy controls. Heart Lung. 2002;31(2): 94-101.

23. Cline CM, Willenheimer RB, Erhardt LR, Wiklund I, Israelsson BY. Health-related quality of life in elderly patients with heart failure. Scand Cardiovasc J. 1999;33(5):278-285.

24. Rodríguez-Artalejo F, Guallar-Castillón P, Pascual CR, et al. Health-related quality of life as a predictor of hospital readmission and death among patients with heart failure. Arch Intern Med. 2005;165(11): 1274-1279.

25. Friedman MM. Gender differences in the health related quality of life of older adults with heart failure. Heart Lung. 2003;32(5):320-327.

26. Bennett SJ, Perkins SM, Lane KA, Deer M, Brater DC, Murray MD. Social support and health-related quality of life in chronic heart failure patients. Qual Life Res. 2001;10(8):671-682.

27. Terzić Z, Marinković J, Draganić G, Ljubić B, Seferović J. [Measuring quality of life in patients with heart failure]. Srp Arh Celok Lek. 2005;133(9-10):412-416. Serbian.

28. Swedberg K, Cleland J, Dargie H, et al; for Task Force for the Diagnosis and Treatment of Chronic Heart Failure of the European Society of Cardiology. Guidelines for the diagnosis and treatment of chronic heart failure: executive summary (update 2005): The Task Force for the Diagnosis and Treatment of Chronic Heart Failure of the European Society of Cardiology. Eur Heart J. 2005;26(11):1115-1140.

29. Rector TS, Kubo SH, Cohn JN. Patients' self-assessment of their congestive heart failure, part 2: content, reliability and validity of a new measure, the Minnesota Living with Heart Failure questionnaire. Heart Failure. 1987;3:198-209.

30. Rector TS, Kubo SH, Cohn JN. Validity of the Minnesota Living with Heart Failure questionnaire as a measure of therapeutic response to enalapril or placebo. Am J Cardiol. 1993;71(12):1106-1107.

31. Rinaldi P, Mecocci P, Benedetti C, et al. Validation of the five-item geriatric depression scale in elderly subjects in three different settings. J Am Geriatr Soc. 2003;51(5):694-698.

32. Folstein MF, Folstein SE, McHugh PR. "Mini-mental state”. A practical method for grading the cognitive state of patients for the clinician. J Psychiatr Res. 1975;12(3):189-198.

33. Creditor MC. Hazards of hospitalization of the elderly. Ann Intern Med. 1993;118(3):219-223.
34. Luttik ML, Jaarsma T, Veeger N, van Veldhuisen DJ. Marital status, quality of life, and clinical outcome in patients with heart failure. Heart Lung. 2006;35(1):3-8.

35. Barbareschi G, Sanderman R, Leegte IL, van Veldhuisen DJ, Jaarsma T. Educational level and the quality of life of heart failure patients: a longitudinal study. J Card Fail. 2011;17(1):47-53.

36. Clark DO, Tu W, Weiner M, Murray MD. Correlates of health-related quality of life among lower-income, urban adults with congestive heart failure. Heart Lung. 2003;32(6):391-401

37. Bekelman DB, Havranek EP, Becker DM, et al. Symptoms, depression, and quality of life in patients with heart failure. J Card Fail. 2007;13(8): 643-648.

38. Heckman GA, Patterson CJ, Demers C, St Onge J, Turpie ID, McKelvie RS. Heart failure and cognitive impairment: challenges and opportunities. Clin Interv Aging. 2007;2(2):209-218.

39. Pressler SJ, Subramanian U, Kareken D, et al. Cognitive deficits and health-related quality of life in chronic heart failure. J Cardiovasc Nurs. 2010;25(3):189-198

40. Sohani ZN, Samaan Z. Does depression impact cognitive impairment in patients with heart failure? Cardiol Res Pract. 2012;2012:524325.

41. Lader E, Egan D, Hunsberger S, Garg R, Czajkowski S, McSherry F. The effect of digoxin on the quality of life in patients with heart failure. $J$ Card Fail. 2003;9(1):4-12.

42. Rogers WJ, Johnstone DE, Yusuf S, et al. Quality of life among 5,025 patients with left ventricular dysfunction randomized between placebo and enalapril: the studies of left ventricular dysfunction. The SOLVD Investigators. J Am Coll Cardiol. 1994;23(2):393-400.

43. Hjalmarson A, Goldstein S, Fagerberg B, et al. Effects of controlledrelease metoprolol on total mortality, hospitalizations, and well-being in patients with heart failure: the Metoprolol CR/XL Randomized Intervention Trial in congestive heart failure (MERIT-HF). MERIT-HF Study Group. JAMA. 2000;283(10):1295-1302.

44. Permpongkosol S. Iatrogenic disease in the elderly: risk factors, consequences, and prevention. Clin Interv Aging. 2011;6:77-82.

45. Flesch M, Erdmann E. The problem of polypharmacy in heart failure. Curr Cardiol Rep. 2006;8(3):217-225.

46. Yancy CW, Jessup M, Bozkurt B, et al. 2013 ACCF/AHA Guideline for the Management of Heart Failure: A Report of the American College of Cardiology Foundation/American Heart Association Task Force on Practice Guidelines. J Am Coll Cardiol. June 5, 2013. [Epub ahead of print.]

47. McHorney CA, Ware JE Jr, Raczek AE. The MOS 36-Item Short-Form Health Survey (SF-36): II. Psychometric and clinical tests of validity in measuring physical and mental health constructs. Med Care. 1993;31(3): 247-263.

48. Green CP, Porter CB, Bresnahan DR, Spertus JA. Development and evaluation of the Kansas City Cardiomyopathy Questionnaire: a new health status measure for heart failure. J Am Coll Cardiol. 2000;35(5):1245-1255.

49. Garin O, Ferrer M, Pont A. Disease-specific health-related quality of life questionnaires for heart failure: a systematic review with meta-analyses. Qual Life Res. 2009;18(1):71-85.

50. Hoekstra T, Jaarsma T, van Veldhuisen DJ, Hillege HL, Sanderman R, Lesman-Leegte I. Quality of life and survival in patients with heart failure. Eur J Heart Fail. 2013;15(1):94-102.

51. Norra C, Skobel EC, Arndt M, Schauerte P. High impact of depression in heart failure: early diagnosis and treatment options. Int J Cardiol. 2008;125(2):220-231.
Clinical Interventions in Aging

\section{Publish your work in this journal}

Clinical Interventions in Aging is an international, peer-reviewed journal focusing on evidence-based reports on the value or lack thereof of treatments intended to prevent or delay the onset of maladaptive correlates of aging in human beings. This journal is indexed on PubMed Central, MedLine, the American Chemical Society's 'Chemical Abstracts

\section{Dovepress}

Service' (CAS), Scopus and the Elsevier Bibliographic databases. The manuscript management system is completely online and includes a very quick and fair peer-review system, which is all easy to use. Visit http://www.dovepress.com/testimonials.php to read real quotes from published authors. 